\title{
The effects of melatonin and thymoquinone on doxorubicin- -induced cardiotoxicity in rats
}

\author{
Yildiz Pehlivan $\mathrm{D}^{1}$, Durdagi $\mathrm{G}^{1}$, Oz Oyar E ${ }^{1}$, Akyol S², Ozbek M³ \\ Izmir Katip Celebi University, Faculty of Medicine, Department of Physiology, Turkey. \\ deniz.yildiz.pehlivan@ikc.edu.tr
}

\section{ABSTRACT}

OBJECTIVES: This study aims to investigate the protective effects of thymoquinone and melatonin on the heart against doxorubicin-induced cardiotoxicity in rats.

BACKGROUND: Melatonin and thymoquinone may play an important role in cardiotoxicity.

METHODS: The subjects were divided into four groups: Control (physiological serum on 5th day),

Doxorubicin (DXR), Doxorubicin+Melatonin (DXR+MEL, $10 \mathrm{mg} / \mathrm{kg}$ melatonin, intraperitoneally), and

Doxorubicin+Thymoquinone (DXR+TQ, $50 \mathrm{mg} / \mathrm{kg}$ thymoquinone, orally). On the 5 th day of the experiment, all groups were injected with $45 \mathrm{mg} / \mathrm{kg}$ DXR into the tail vein. On the 8th day of the experiment, ECG recordings were performed under anaesthesia.

RESULTS: Thymoquinone reduced the PR, QRS and QTc intervals, which were increased by DXR, while melatonin only reduced the QTc interval. Melatonin had a protective effect against the histopathological changes induced by DXR, while TQ did not demonstrate such an effect. DXR increased CK-MB, IL-6, MDA, IL-1, IL-18 levels and decreased SOD in the cardiac tissue. MEL reduced the levels of CK-MB, MDA, NO, SOD, IL-1, IL-6, IL-18. Meanwhile, TQ only reduced CK-MB, IL-1 and IL-18.

CONCLUSION: Our study showed that DXR induces cardiac injury and that melatonin improves biochemical parameters and offers histological protection; while thymoquinone improves ECG parameters and causes partial recovery of biochemical parameters (Tab. 4, Fig. 2, Ref. 41). Text in PDF www.elis.sk KEY WORDS: doxorubicin, cardiotoxicity, ECG, melatonin, thymoquinone.

\section{Introduction}

Doxorubicin is an anthracycline antibiotic that is used in the treatment of various cancers including haematological cancers, solid tumours, and soft tissue sarcomas. The most prominent side effect of DXR is heart failure and cardiac injury.

Certain mechanisms such as oxidative stress, impairment of mitochondrial functions, apoptosis, myofibrillary disarray, disruption of intracellular calcium regulation, suppression of nucleic acid and protein synthesis, and reduced expression of heart-specific genes have been implicated in its toxic effects on the heart muscle (1) (2). However, oxidative stress, impairment of mitochondrial functions and apoptosis are the most prominent factors (3). The notion that oxidative stress plays a key role in the development of DXR-induced cardiomyopathy is corroborated by the increase in reactive oxygen species (ROS), decrease in antioxidant and sulfhydryl groups and increase in lipid peroxidation (4).

${ }^{1}$ Izmir Katip Celebi University, Faculty of Medicine, Department of Physiology, Turkey, ${ }^{2}$ Izmir Katip Çelebi University, Faculty of Medicine, Department of Histology and Embryology, Turkey, and ${ }^{3}$ Celal Bayar University, Faculty of Medicine, Department of Physiology, Turkey

Address for correspondence: Yildiz Pehlivan D, Izmir Katip Celebi University, Faculty of Medicine, Department of Physiology, Turkey.

Acknowledgements: This study was supported by Scientific Research Fund of Izmir Katip Celebi University. Project Number: 2015- ÖNP-TIPF-0016.
Certain antioxidant substances are being investigated with regard to the prevention of DXR-induced cardiotoxicity. One of the antioxidants that have been tested is melatonin which is secreted by the pineal gland. Besides its strong antioxidant effect, it was also reported to have a regulatory effect on the mitochondrial energy metabolism (3) and anti-apoptotic effects (5).

One of the substances that are considered to have a potentially favourable effect in the prevention of DXR cardiomyopathy is thymoquinone. TQ is the most important bioactive ingredient found in black cumin oil (Nigella sativa). Black cumin and TQ were reported to have anticancerogenic, antiulcerogenic, antiinflammatory and antioxidant effects (6). Their favourable effects on cardiac injury induced by certain medications (7) (8) and ischemia-reperfusion (9) have been previously reported; however, very few studies have reported the protective effects of TQ on the heart against DXR-induced toxicity $(10,11)$.

DXR is an indispensable medication in the treatment of cancers. However, its toxic effect must be attenuated as it damages vital organs such as the heart. This study aims to investigate the effects of TQ against DXR-induced cardiotoxicity and to compare this with the preventive effect of melatonin against cardiac injury. Thus, it will allow safer and more effective utilization of DXR, the use of which is restricted due to its serious side effects, in cancer treatment. 


\section{3-759}

\section{Materials and methods}

\section{Experimental animals}

This study was approved by the Celal Bayar University (CBU) Faculty of Medicine Experimental Research Local Ethics Committee (Approval number: 77.637.435-51, Date: 09/06/2015).

This study included 32 male Wistar albino rats weighing 230 350 g. Rats were obtained from the CBU Experimental Animal Research and Application Centre and maintained under uniform laboratory conditions throughout the experiment. They were kept in a laboratory where a temperature of $22 \pm 2{ }^{\circ} \mathrm{C}$, a 12-hour light:12hour dark cycle, and a humidity of $40 \pm 20 \%$ were maintained. All rats were provided with tap water to drink and a standard pellet diet.

These 32 animals were divided into 4 groups, each composed of 8 rats. Some of the animals died during the experiment (because DXR is toxic) and were excluded from the study. Medications were administered over a 7-day period and the rats were sacrificed on the 8th day.

\section{Control group}

Injected intravenously (iv) with a single dose of physiological serum through the tail vein on the 5 th day.

Doxorubicin group

Injected iv with a single dose of $45 \mathrm{mg} / \mathrm{kg} /$ day DXR through the tail vein on the 5 th day (12).

Doxorubicin+Melatonin group

Injected intraperitoneally (ip) with $10 \mathrm{mg} / \mathrm{kg}$ /day melatonin for 7 days. Injected iv with a single dose of $45 \mathrm{mg} / \mathrm{kg} /$ day DXR on the 5 th day.

Doxorubicin+ Thymoquinone group

$50 \mathrm{mg} / \mathrm{kg}$ /day TQ solution dissolved in ethanol and buffered with phosphate buffered saline (PBS) was mixed into pellet diet and administered orally for 7 days. Injected iv with a single dose of $45 \mathrm{mg} / \mathrm{kg} /$ day DXR on the 5 th day.

Administered Chemicals

Doxorubicin hydrochloride, Melatonin, Thymoquinone, and Sodium pentobarbital were acquired from the Sigma-Aldrich Company and physiological serum was obtained from a pharmacy.

\section{Analysis methods}

Anaesthesia and collection of samples

Rats were injected ip with $50 \mathrm{mg} / \mathrm{kg}$ Sodium pentobarbital on the 8 th day of the experiment. ECG recordings were performed under anaesthesia, after which the rats were sacrificed, and their cardiac tissues were extracted.

Evaluation of ECG Recordings

ECG (DII derivation) was recorded while the rats were under anaesthesia. The recordings were performed using the "PowerLab/ SP8" bioelectric recording device and the Lab Chart 7 computer software (ADInstruments, Australia). Durations of the QRS complex, QT interval, PR interval and QTc (Corrected QT; Bazett's Formula: $\mathrm{QTc}=\mathrm{QT} / \sqrt{\mathrm{RR}}$ ) were measured. Statistical analyses were conducted by computing the mean of five consecutive heartbeats on ECG.

\section{Histological evaluation}

Left ventricular tissue samples collected from the rats were stained with haematoxylin-eosin (H\&E) and examined using an Olympus Bx43 light microscope with an attached camera (Olympus SC100).

The samples were evaluated with regard to the disorganization of muscle fibres, interstitial oedema, interstitial haemorrhage, nuclear degeneration, perinuclear vacuolization, inflammatory cells, and fibrosis; and histopathological changes were scored. Each histopathological change was given a score of "1", while no change was scored as " 0 ". The severity of histopathological damage was evaluated based on the total score of the parameters (0-2 points: No damage; $3-4$ points: Mild damage; $5-7$ points: Damage) (13).

\section{Evaluation of biochemical parameters}

Total oxidant and antioxidant levels (TOS (14) and TAS (15) (Rel Assay Diagnostics)), glutathione peroxidase (GPx (Randox Ransel)) (16) and superoxide dismutase (SOD (Randox Ransod)) (17) tissue protein hemolysate, haemoglobin levels were determined with the spectrophotometric method using an autoanalyzer; malondialdehyde (MDA) (18) and catalase (CAT) (19) were assessed with the manual spectrophotometric method.

Nitric oxide (NO (Yehua Biological Technology)), hypoxiainducible factor (HIF-1 $\alpha$ (YH-Biosearch)), creatine kinase myocardial band (CK-MB (Shangai LZ Biotech Co)), tumour necrosis factor alpha (TNF- $\alpha$ (YH-Biosearch)), interleukin-1 (IL-1 (YHBiosearch)), interleukin-6 (IL-6 (YH-Biosearch)), interleukin-18 (IL-18 (YH-Biosearch)) levels were measured with the ELISA assay.

Tab. 1. Values of ECG parameters of the groups.

\begin{tabular}{|c|c|c|c|c|c|}
\hline Groups & $\begin{array}{c}\mathrm{RR}(\mathrm{sec}) \\
\mathrm{Mean} \pm \mathrm{SD}\end{array}$ & $\begin{array}{l}\text { QRS }(\mathrm{sec}) \\
\text { Mean } \pm \text { SD }\end{array}$ & $\begin{array}{c}\mathrm{PR}(\mathrm{sec}) \\
\mathrm{Mean} \pm \mathrm{SD}\end{array}$ & $\begin{array}{c}\text { QT (sec) } \\
\text { Mean } \pm \text { SD }\end{array}$ & $\begin{array}{l}\text { QTc }(\mathrm{sec}) \\
\text { Mean } \pm \text { SD }\end{array}$ \\
\hline Control & $0.237 \pm 0.018$ & $0.016 \pm 0.001$ & $0.043 \pm 0.004$ & $0.077 \pm 0.010$ & $0.158 \pm 0.019$ \\
\hline DXR & $0.269 \pm 0.054^{\mathrm{b}}$ & $0.026 \pm 0.007^{\mathrm{c}}$ & $0.063 \pm 0.013^{\mathrm{c}}$ & $0.129 \pm 0.021^{\mathrm{c}}$ & $0.250 \pm 0.037^{\mathrm{c}}$ \\
\hline DXR+MEL & $0.307 \pm 0.093^{\mathrm{c}}$ & $0.023 \pm 0.002^{\mathrm{c}}$ & $0.065 \pm 0.018^{\mathrm{c}}$ & $0.120 \pm 0.029^{c}$ & $0.217 \pm 0.027^{\text {c.d }}$ \\
\hline $\mathrm{DXR}+\mathrm{TQ}$ & $0.352 \pm 0.076^{\text {c.f.g }}$ & $0.022 \pm 0.005^{\text {c.d.g }}$ & $0.057 \pm 0.013^{\text {c.d.g }}$ & $0.124 \pm 0.035^{\mathrm{c}}$ & $0.207 \pm 0.044^{\mathrm{c} . \mathrm{d}}$ \\
\hline$\underline{\mathrm{p}}$ & $<0.001$ & $<0.001$ & $<0.001$ & $<0.001$ & $<0.001$ \\
\hline
\end{tabular}

SD: Standard Deviation, DXR: Doxorubicin, MEL: Melatonin, TQ: Thymoquinone a: Significant difference from the control group (p $<0.05)$, b: Significant difference from the control group $(p<0.01)$, c: Significant difference from the control group $(p<0.001)$, d: Significant difference from the DXR group ( $<0.05)$, e: Significant difference from the DXR group $(\mathrm{p}<0.01)$, f: Significant difference from the DXR group $(\mathrm{p}<0.001)$, g: Significant difference from the DXR + MEL group ( $<0.05)$, h: Significant difference from the DXR+MEL group $(\mathrm{p}<0.01)$, 1: Significant difference from the DXR+MEL group $(\mathrm{p}<0.001)$. 

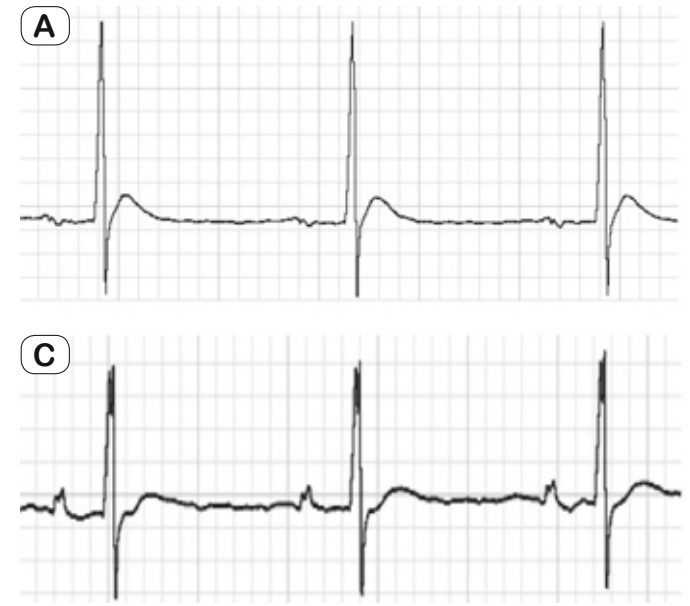
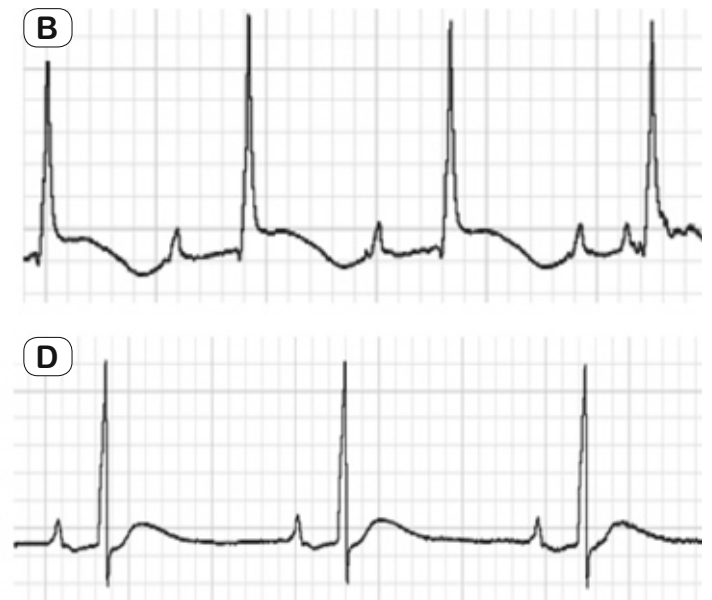

Fig. 1. ECG (DII derivation) recording obtained in the experiment (A) Control group; (B) DXR group; (C) DXR+MEL group; (D) DXR+TQ group.

\section{Statistical analysis}

All statistical analyses were conducted using the SPSS 22.0 (Statistical Package for Social Sciences) statistics software. Crossgroup differences were analysed using the Kruskal-Wallis variance analysis and the Mann-Whitney U test. In the statistical analyses of histological findings, the chi-square test was applied. Mean and standard deviation values were computed and cases associated with a p-value below 0.05 were considered significant.

\section{Results}

\section{ECG results}

Table 1 present results and statistical analyses of ECG parameters. When ECG parameters of rats in DXR, DXR+MEL, $\mathrm{DXR}+\mathrm{TQ}$ groups were compared with the control groups, RR, $\mathrm{PR}, \mathrm{QRS}, \mathrm{QT}$ and $\mathrm{QT}_{\mathrm{c}}$ intervals were revealed longer (Tab. 1).

Compared with the DXR group, the DXR+MEL group demonstrated a shorter QT time $(\mathrm{p}<0.05)$. Compared with the DXR group, the DXR+TQ group demonstrated shorter PR, QRS and QT times $(p<0.05)$ and a longer $R R$ interval $(p<0.001)$. Compared with the DXR+MEL group, the DXR+TQ group showed shorter $P R$ and $Q R S$ intervals and a longer $R R$ interval $(p<0.05)$ (Fig. 1).

\section{Histological findings}

Mean damage scores obtained by the examination of the tissues under a light microscope are presented in Tables 2 and 3 . The mean score of the control group was lower than those of the DXR and

Tab. 2. Distribution of the animals according to the severity of histopathological left ventricular injury.

\begin{tabular}{lcccc}
\hline Groups & $\begin{array}{c}\text { No damage } \\
\mathrm{n}(\%)\end{array}$ & $\begin{array}{c}\text { Mild damage } \\
\mathrm{n}(\%)\end{array}$ & $\begin{array}{c}\text { Damage } \\
\mathrm{n}(\%)\end{array}$ & $\begin{array}{c}\text { Total } \\
\mathrm{n}(\%)\end{array}$ \\
\hline Control & $6(85.7)$ & $1(14.3)$ & $0(0.0)$ & $7(100)$ \\
DXR & $0(0.0)$ & $0(0.0)$ & $6(100)$ & $6(100)$ \\
DXR + MEL & $4(57.1)$ & $2(28.6)$ & $1(14.3)$ & $7(100)$ \\
DXR + TQ & $0(0.0)$ & $0(0.0)$ & $6(100)$ & $6(100)$ \\
\hline
\end{tabular}

$\mathrm{DXR}+\mathrm{TQ}$ groups with statistical significance $(\mathrm{p}<0.01)$. The mean score of the DXR+MEL group was significantly different than that of the DXR group $(p<0.01)$. The mean score of the DXR+TQ group was lower than that of the DXR group, however this difference was not statistically significant. Compared with the DXR+MEL group, the DXR+TQ group showed a significant increase $(\mathrm{p}<0.01)$ (Fig. 2).

\section{Biochemical findings}

Results of the biochemical parameters measured in the experimental groups and statistical analyses are presented in Table 4.

CK-MB levels were found to be significantly higher in the DXR group compared with the control group $(\mathrm{p}<0.05)$. Compared with the DXR group, both the DXR+MEL and DXR+TQ groups showed significantly lower levels $(p<0.05)$. However, the $\mathrm{DXR}+\mathrm{MEL}$ and DXR+TQ groups were not significantly different in terms of the amount of decrease in CK-MB levels.

When evaluated with regard to interleukin-1 levels, the DXR group showed higher levels than the control group $(p<0.01)$. Compared with the DXR group, both the DXR+MEL and DXR+TQ groups demonstrated significantly lower levels $(\mathrm{p}<0.01)$. On the other hand there was not a significant difference between the DXR+MEL and DXR+TQ groups in terms of the amount of decrease in IL-1 levels.

Tab. 3. Mean histopathological left ventricular injury scores.

\begin{tabular}{lcc}
\hline Groups & $\mathrm{n}$ & Mean \pm SD \\
\hline Control & 7 & $1.0 \pm 1.29$ \\
DXR & 6 & $6.16 \pm 0.75^{\mathrm{b}}$ \\
DXR + MEL & 7 & $2.42 \pm 1.71^{\mathrm{e}}$ \\
DXR + TQ & 6 & $5.83 \pm 0.98^{\mathrm{b} . \mathrm{h}}$ \\
\hline SD: Standard Deviation, DXR: Doxorubicin, Mel: Melatonin, TQ. Thymoquinone
\end{tabular}

SD: Standard Deviation, DXR: Doxorubicin, Mel: Melatonin, TQ: Thymoquinone a: Significant difference from the control group $(\mathrm{p}<0.05)$, b: Significant difference from the control group $(\mathrm{p}<0.01)$, c: Significant difference from the control group $(p<0.001)$, d: Significant difference from the DXR group $(p<0.05)$, e: Significant difference from the DXR group $(\mathrm{p}<0.01)$, f: Significant difference from the DXR group $(p<0.001)$, g: Significant difference from the DXR+MEL group $(p<0.05)$, $\mathrm{h}$ : Significant difference from the DXR+MEL group $(\mathrm{p}<0.01)$, 1: Significant difference from the DXR+MEL group $(\mathrm{p}<0.001)$. 
Tab. 4. Values of biochemical parameters.

\begin{tabular}{|c|c|c|c|c|}
\hline & $\begin{array}{c}\text { Control } \\
(n=7) \\
\text { Mean } \pm \text { SD }\end{array}$ & $\begin{array}{c}\text { DXR } \\
(n=6) \\
\text { Mean } \pm \text { SD }\end{array}$ & $\begin{array}{c}\text { DXR+MEL } \\
(n=7) \\
\text { Mean } \pm \text { SD }\end{array}$ & $\begin{array}{c}\mathrm{DXR}+\mathrm{TQ} \\
(\mathrm{n}=6) \\
\text { Mean } \pm \text { SD }\end{array}$ \\
\hline $\begin{array}{l}\text { CK-MB } \\
\text { (ng/mg protein) }\end{array}$ & $7.29 \pm 1.77$ & $12.40 \pm 2.57^{\mathrm{a}}$ & $6.73 \pm 2.11^{\mathrm{d}}$ & $6.23 \pm 2.21^{\mathrm{d}}$ \\
\hline $\begin{array}{l}\text { HIF-1 } \alpha \\
\text { (ng/mg protein) }\end{array}$ & $2.27 \pm 0.28$ & $2.56 \pm 1.35$ & $1.62 \pm 0.59$ & $2.19 \pm 0.90$ \\
\hline $\begin{array}{l}\text { TNF- } \alpha \\
\text { (pg/mg protein) }\end{array}$ & $101.18 \pm 20.84$ & $131.50 \pm 45.49$ & $103.35 \pm 3.97$ & $105.73 \pm 4.63$ \\
\hline $\begin{array}{l}\text { IL1 } \\
\text { (pg/mg protein) }\end{array}$ & $30.09 \pm 6.47$ & $64.03 \pm 18.68^{\mathrm{b}}$ & $22.30 \pm 5.12^{\mathrm{e}}$ & $22.12 \pm 8.57^{\mathrm{e}}$ \\
\hline $\begin{array}{l}\text { IL6 } \\
\text { (ng/g protein) }\end{array}$ & $3.64 \pm 1.05$ & $8.48 \pm 2.83^{\mathrm{a}}$ & $2.55 \pm 0.84^{\mathrm{e}}$ & $4.94 \pm 1.84^{\mathrm{g}}$ \\
\hline $\begin{array}{l}\text { IL18 } \\
\text { (pg/mg protein) }\end{array}$ & $136.83 \pm 9.29$ & $231.96 \pm 52.08^{b}$ & $62.96 \pm 11.59^{\text {b.e }}$ & $107.84 \pm 34.31^{\text {e.g }}$ \\
\hline $\begin{array}{l}\text { MDA } \\
\text { (nmol/mg protein) }\end{array}$ & $242.33 \pm 32.77$ & $315.57 \pm 63.57^{\mathrm{a}}$ & $177.85 \pm 97.45^{\mathrm{d}}$ & $267.16 \pm 109.41$ \\
\hline $\begin{array}{l}\text { NO } \\
(\mu \mathrm{mol} / \mathrm{g} \text { protein })\end{array}$ & $62.86 \pm 8.94$ & $91.54 \pm 23.99$ & $31.83 \pm 4.38^{\mathrm{a} . \mathrm{d}}$ & $60.28 \pm 26.13$ \\
\hline $\begin{array}{l}\text { SOD } \\
\text { (U/mg protein) } \\
\end{array}$ & $8.90 \pm 1.22$ & $6.93 \pm 1.41^{\mathrm{a}}$ & $5.87 \pm 1.70^{\mathrm{b}}$ & $9.28 \pm 2.58^{\mathrm{g}}$ \\
\hline $\begin{array}{l}\text { GPx } \\
\text { (U/mg protein) }\end{array}$ & $1.66 \pm 0.83$ & $1.57 \pm 0.39$ & $1.06 \pm 0.40$ & $1.20 \pm 0.24$ \\
\hline $\begin{array}{l}\text { CAT } \\
(\mathrm{k} / \mathrm{g} \text { protein }) \\
\end{array}$ & $10.72 \pm 8.25$ & $5.80 \pm 4.18$ & $3.95 \pm 1.29$ & $3.63 \pm 1.23$ \\
\hline $\begin{array}{l}\text { TAS } \\
\text { (mmol/g protein) }\end{array}$ & $0.11 \pm 0.03$ & $0.12 \pm 0.03$ & $0.08 \pm 0.04$ & $0.15 \pm 0.07$ \\
\hline $\begin{array}{l}\text { TOS } \\
(\mu \mathrm{mol} / \mathrm{g} \text { protein })\end{array}$ & $0.47 \pm 0.15$ & $0.68 \pm 0.39$ & $0.59 \pm 0.45$ & $0.85 \pm 0.82$ \\
\hline
\end{tabular}

SD: Standard Deviation, DXR: Doxorubicin, Mel: Melatonin, TQ: Thymoquinone a: Significant difference from the control group $(p<0.05)$, b: Significant difference from the control group $(p<0.01)$, c: Significant difference from the control group $(p<0.001)$, d: Significant difference from the DXR group $(p<0.05)$, e: Significant difference from the DXR group $(p<0.01)$, f: Significant difference from the DXR group $(p<0.001)$, g: Significant difference from the DXR+MEL group $(\mathrm{p}<0.05)$, h: Significant difference from the DXR+MEL group $(\mathrm{p}<0.01)$, 1: Significant difference from the DXR+MEL group $(\mathrm{p}<0.001)$
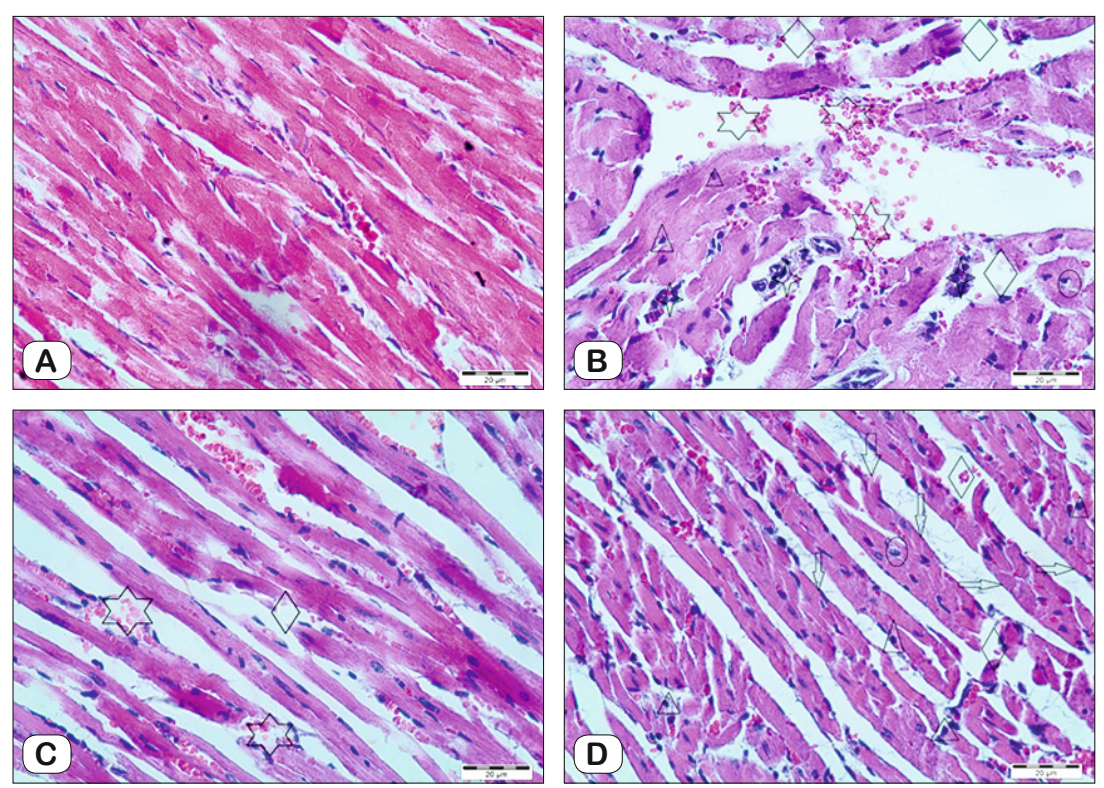

Fig. 2. Images of the left ventricle obtained from the (A) Control group; (B) DXR group; (C) DXR+MEL group; (D) DXR+TQ group. Haematoxylin\&Eosin staining, bar: $20 \mu \mathrm{m}$.

$O$ : perinuclear vacuolization, $\triangle$ : nuclear degeneration, $\Sigma$ : interstitial haemorrhage, $\checkmark$ : disorganization of fibres, $\prec$ : infiltration, $\downarrow$ : fibrosis, $\Rightarrow$ : interstitial edema
Compared with the control group, the DXR group showed significantly higher IL-6 levels $(p<0.05)$. In comparison to the DXR group, the DXR+MEL group showed a significant decrease $(p<0.01)$. When compared with regard to the amount of decrease in IL-6, a statistically significant difference was determined between the DXR+MEL and DXR+TQ groups $(\mathrm{p}<0.05)$.

When evaluated with regard to the levels of IL-18, which is a proinflammatory cytokine, the DXR group showed a significant increase $(\mathrm{p}<0.01)$; the DXR+MEL group a significant decrease $(\mathrm{p}<0.01)$; and the $\mathrm{DXR}+\mathrm{TQ}$ group a non-significant decrease compared to the control group. Compared with the DXR group, both the DXR+MEL and DXR+TQ groups demonstrated markedly lower levels $(p<0.01)$. The decrease determined in the DXR+MEL group was more pronounced than that in the $\mathrm{DXR}+\mathrm{TQ}$ group, and this difference was significant $(\mathrm{p}<0.05)$.

Levels of MDA, which is an end product of lipid peroxidation, showed a statistically significant increase in the DXR group compared to the control group $(\mathrm{p}<$ 0.05). Compared with the DXR group, the DXR+MEL group showed a significant decrease $(p<0.05)$, while the decrease observed in the DXR+TQ group did not reach statistical significance.

NO levels demonstrated a non-significant increase in the DXR group compared to the control group. Compared with both, control and DXR group, the DXR+MEL group showed a significant decrease $(p<0.05)$.

When levels of the SOD enzyme, which is an endogenous antioxidant and converts superoxide to hydrogen peroxide, were compared with the control group, a significant decrease was found in the DXR $(\mathrm{p}<$ $0.05)$ and DXR+MEL group $(\mathrm{p}<0.01)$ and a non-significant increase was observed in the DXR+TQ group. When compare with DXR+MEL group, DXR+TQ group showed a significant increase $(p<0.05)$.

\section{Discussion}

\section{Evaluation of Electrocardiography Results}

Electrocardiographic effects of doxorubicin-induced cardiotoxicity

Compared with the control group, the DXR group demonstrated significantly lon- 
ger PR, QRS, QT and QTc intervals. Further, the increase determined in the RR interval indicates that DXR slows down the heart rate. There are many studies in the literature that support our results. Rats (20) (21) (22) and mice (23) (24) injected with DXR were reported to show significantly lower heart rates. Again, QRS (20), PR (21) and QT (20) (21) (22) intervals in rats, and QRS (24) and QT (23) intervals in mice were reported to be extended. Mantawy and colleagues (25) reported that doxorubicin application induced a significant decrease in the heart rate and an increase in QRS, PR, QTc intervals in comparison to controls.

The increase in the RR interval reveals that the sinoatrial node function is impacted. The DXR-induced increases in PR and QRS intervals indicate that, both, atrioventricular and intraventricular conduction are delayed. A longer QT interval suggests an increase in the repolarization time and may indicate a delay in the outflow of $\mathrm{K}^{+}$ions from the cell.

\section{Electrocardiographic Effects of Melatonin}

In our study the melatonin group showed a significantly shorter QTc interval than the DXR group. These results suggest that melatonin decreases repolarization time. In parallel to our results, Ashgari and colleagues (26) reported that when melatonin was administered against aluminium phosphide-induced cardiotoxicity, caused a dose-dependent decrease in QRS and QTc intervals.

According to our results, the DXR+MEL group showed a longer RR interval compared to the controls. Certain studies have reported melatonin to decrease heart rate (27) (28). Dose-dependent intravenous injections of melatonin were reported to cause bradycardia via sympathetic inhibition or parasympathetic stimulation (29). Another study stated that melatonin decreases the heart rate by modulating the baroreceptor reflex that regulates the heart rate and that this effect was mediated by the melatonin receptors found in the area postrema located outside of the bloodbrain barrier (30).

\section{Electrocardiographic effects of thymoquinone}

The QRS, PR, QT and QTc intervals of the DXR+TQ group were longer compared to the control group and shorter compared to the DXR group. QRS and PR results suggest that TQ shortens atrioventricular and intraventricular conduction times in the heart. The alleviation of the DXR-induced increase in the QTc interval by TQ indicates that TQ influences repolarization. The DXR+TQ group showed a significantly longer RR interval than both, the control and the DXR groups. There is data in the literature suggesting that Nigella Sativa oil decreases heart rate (31). The results of our study show that TQ can prevent the DXR-induced impairment of ECG parameters (except for the RR interval).

\section{Evaluation of histological findings}

When compared with the control group, DXR was found to have caused tissue damage in all experimental groups. The histopathological changes induced by DXR were significantly improved by melatonin, whereas the improvement caused by TQ was not pronounced enough to reach statistical significance. In the literature, melatonin has been reported to reduce the cardiac injury induced by DXR (32) (33) and 2,3,7,8-Tetrachlorodibenzo-p-dioxin (27).

\section{Evaluation of biochemical findings}

CK-MB is an isoenzyme that reflects cardiac damage in the acute phase. The CK-MB levels of the DXR group were determined to be higher than those of the control group. The administration of melatonin or thymoquinone with DXR prevented the DXR-induced increase in CK-MB. These results are in accordance with the literature. Isoproterenol-induced infarction (28), Adriamycin (34) and aluminum phosphide- induced cardiotoxicity (26) have reported that melatonin causes a dose-dependent decrease in CK-MB levels. Elevated CK-MB levels that arise from cyclophosphamide- (8) and DXR-induced (35) cardiotoxicity and ischemia-reperfusion (36) were reported to be significantly reduced by TQ. Similarly, the administration of Nigella Sativa oil against acetate-induced cardiotoxicity was reported to lower CK-MB levels (31).

Superoxide radical is a reactive oxygen species. Elevated ROS production leads to oxidative stress. ROS activate proinflammatory mediators. Compared with the control group, the DXR group showed significantly higher levels of proinflammatory cytokines (IL-1, IL-6 and IL-18). We found that the administration of melatonin and TQ prevented DXR-induced elevated cytokine levels. These results are in congruence with the literature. Melatonin was reported in one study to supress cytokines and the expression of inflammatory mediators (37). Studies have reported thymoquinone to reduce oxidative stress and inflammation (38) and IL-2 levels (35).

MDA is a product of lipid peroxidation and is an important indicator of free radical-induced damage. DXR disrupts membrane functions by increasing free radicals and leads to cardiotoxic effects. In the present study, the DXR group was found to have a significantly higher MDA value than the control group. Melatonin prevented the DXR-induced elevated MDA levels. There are studies in the literature that have reported melatonin to decrease MDA levels $(26,27,28,33)$. In the present study, the fact that TQ was not able to generate a significant difference in MDA levels despite causing a decrease towards control levels can be explained by the large standard deviation values. In the literature, elevated MDA levels induced by DXR (35), ischemia-reperfusion (36) and isoproterenol (38) were reported to be reduced by TQ; and high MDA levels induced by cyclosporin A (7) and acetate (31) were reported to be reduced by Nigella sativa applications.

$\mathrm{NO}$ is a reactive radical. Physiological concentrations of reactive NO are thought to suppress the apoptotic process. Elevated NO levels can have pro-apoptotic effects as the mentioned protective effect is eliminated. Compared with the control group, DXR caused an increase in NO. However, this difference was not statistically significant. Melatonin and thymoquinone are expected to inhibit NO production via their antioxidant effects. The administration of melatonin with DXR caused a significant decrease in NO compared to the DXR group. In one study, melatonin was shown to have a NO scavenging effect (39). Compared with the group injected with DXR, we determined a decrease in the NO values of the group treated with thymoquinone, however this difference was not statistically significant.

Levels of the SOD enzyme were significantly lower in both, the DXR and the DXR+MEL groups when compared to the control group. DXR causes an increase in superoxide radical production by 
suppressing the activity of SOD (40). The decrease in SOD levels induced by melatonin can be linked to no need for SOD activity due to the free radical scavenging effect of melatonin (41). The group treated with TQ demonstrated an increase in SOD levels, albeit not significant. The literature contains evidence supporting the notion that TQ increases SOD levels $(35,36)$.

\section{General review}

In this study the electrocardiographic, biochemical and histological data obtained reveal a damaging effect of DXR on the heart.

According to the results of our study, while melatonin is more successful in improving the biochemical parameters and histopathological changes; thymoquinone is more successful in improving ECG parameters. The protective effects of melatonin on the heart have previously been reported by various researchers $(13,32,33)$. Literature data on thymoquinone is quite limited and studies have reported thymoquinone to be a cardioprotective agent against DXR $(10,11)$. We conclude that further studies are needed to investigate the cardioprotective effect of thymoquinone with regard to dosages and treatment durations.

\section{References}

1. Takemura G, Fujiwara H. Doxorubicin-induced cardiomyopathy. From the cardiotoxic mechanisms to management. Prog Cardiovasc Dis 2007; 49 (5): 330-352.

2. Raj S, Franco VI, Lipshultz SE. Anthracycline-induced cardiotoxicity: A review of pathophysiology, diagnosis, and treatment. Curr Treat Options Cardiovasc Med 2014; 16: 315-329.

3. Govender J, Loos B, Marais E, Engelbrecht A-M. Mitochondrial catastrophe during doxorubicin-induced cardiotoxicity: A review of the protective role of melatonin. J Pineal Res 2014; 57: 367-380.

4. Chatterjee K, Zhang J, Honbo N, Karliner JS. Doxorubicin cardiomyopathy. Cardiology 2010; 115: 155-162.

5. Dobsak P, Siegelova J, Eicher J, et al. Melatonin protects against ischemia-reperfusion injury and inhibits apoptosis in isolated working rat heart. Pathophysiology 2003; 9 (3): 179-187.

6. Bacak Güllü E, Aveı G. Thymoquinone: The bioactive component of nigella sativa. Kocatepe Vet J 2013; 6 (1): 51-61.

7. Uz E, Uz B, Selcoki Y, et al. Cardioprotective effects of nigella sativa oil on cyclosporine A-induced cardiotoxicity in rats. Basic Clin Pharmacol Toxicol 2008; 103: 574-580.

8. Nagi MN, Al-Shabanah OA, Hafez MM, Sayed-Ahmed MM. Thymoquinone supplementation attenuates cyclophosphamide-induced cardiotoxicity in rats. J Biochem Mol Toxicol 2011; 25 (3): 135-142.

9. Seif AA. Nigella sativa attenuates myocardial ischemic reperfusion injury in rats. J Physiol Biochem 2013; 69: 937-944.

10. Al-Shabanah OA, Badary OA, Nagi MN, Al-Gharably NM, AlRikabi AC, Al-Bekairi AM. Thymoquinone protects against doxorubicininduced cardiotoxicity without compromising its antitumor activity. J Exp Clin Cancer Res 1998; 17 (2): 193-198.

11. Nagi MN, Mansour MA. Protective effect of thymoquinone against doxorubicin-induced cardiotoxicity in rats: A possible mechanism of protection. Pharmacol Res 2000; 41 (3): 283-289.
12. Öz E, İlhan MN. Effects of melatonin in reducing the toxic effects of doxorubicin. Molecular and Cellular Biochemistry 2006; 286: 11-15.

13. Demir F, Narin F, Akgün H, et al. Doksorubisin ile oluş̧urulmuş deneysel kardiyotoksisite üzerine melatoninin etkisi. Cocuk Sagligi ve Hast Derg 2004; 47 (4): 260-268.

14. Emsen B. The antioxidant and antigenotoxic potential of peltigera canina and umbilicaria nylanderiana based on their phenolic profile. Farmacia 2019; 67 (5): 912-921.

15. Jablecka A, Checinski P, Krauss H, Micker M, Ast J. The influence of two different doses of L-arginine oral supplementation on nitric oxide (NO) concentration and total antioxidant status (TAS) in atherosclerotic patients. Med Sci Monit 2004; 10 (1): 29-33.

16. Paglia DE, Valentine WN. Studies on the quantitative and qualitative characterization of erythrocyte glutathione peroxidase. J Lab Clin Med 1967; 70 (1): 158-169.

17. Wooliams JA, Wiener G, Anderson PH, McMurray CH. Variation in the activities of glutathione peroxidase and superoxide dismutase and in the concentration of copper in the blood in various breed crosses of sheep. Res Vet Sci 1983; 34: 253-256.

18. Draper HH, Hadley M. Malondialdehyde determination as index of lipid peroxidation. Methods Enzymol 1990; 186: 421-431.

19. Kıranoglu S, Sinan S, Gencer N, Köckar F, Arslan O. In vivo effects of oral contraceptives on paraoxonase, catalase and carbonic anhydrase enzyme activities on mouse. Biol Pharm Bull 2007; 30 (6): 10481051.

20. Jensen RA, Acton EM, Peters JH. Doxorubicin cardiotoxicity in the rat: Comparison of electrocardiogram, transmembrane potential, and structural effects. J Cardiovasc Pharmacol 1984; 6 (1): 186-200.

21. Xin YF, Zhou GL, Deng ZY, et al. Protective effect of lycium barbarum on doxorubicin-induced cardiotoxicity. Phyther Res 2007; 21 : $1020-1024$.

22. Gül SS, Aygün H. Cardioprotective effect of vitamin D and melatonin on doxorubicin-induced cardiotoxicity in rat model: An electrocardiographic, scintigraphic and biochemical study. Eur Res J 2019; 5 (4): 649-657.

23. Naidu MUR, Vijay Kumar K, Krishna Mohan I, Sundaram C, Singh S. Protective effect of gingko biloba extract against doxorubicininduced cardiotoxicity in mice. Indian J Exp Biol 2002; 40: 894-900.

24. Kojima R, Toyama Y, Tsuyoshi Ohnishi S. Protective effects of an aged garlic extract on doxorubicin-induced cardiotoxicity in the mouse. Nutr Cancer 1994; 22: 163-173.

25. Mantawy EM, El-Bakly WM, Esmat A, Badr AM, El-Demerdash E. Chrysin alleviates acute doxorubicin cardiotoxicity in rats via suppression of oxidative stress, inflammation and apoptosis. Eur J Pharmacol 2014; 728: 107-118.

26. Asghari MH, Moloudizargari M, Baeeri M, et al. On the mechanisms of melatonin in protection of aluminum phosphide cardiotoxicity. Arch Toxicol 2017; 91: 3109-3120.

27. Sarihan ME, Parlakpinar H, Ciftci O, et al. Protective effects of melatonin against 2,3,7,8-tetrachlorodibenzo-p-dioxin-induced cardiac injury in rats. Eur J Pharmacol 2015; 762: 214-220.

28. Patel V, Upaganlawar A, Zalawadia R, Balaraman R. Cardioprotective effect of melatonin against isoproterenol induced myocardial infarction in rats: A biochemical, electrocardiographic and histoarchitectural evaluation. Eur J Pharmacol 2010; 644: 160-168. 
29. Chuang JI, Chen SS, Lin MT. Melatonin decreases brain serotonin release, arterial pressure and heart rate in rats. Pharmacology 1993; 47: 91-97.

30. Campos LA, Cipolla-Neto J, Michelini LC. Melatonin modulates baroreflex control via area postrema. Brain Behav 2013; 3 (2): 171-177.

31. Ahmed MA, Hassanein KMA. Cardio protective effects of nigella sativa oil on lead induced cardio toxicity: Anti inflammatory and antioxidant mechanism. J Physiol Pathophysiol 2013; 4 (5): 72-80.

32. Liu X, Chen Z, Chua CC, et al. Melatonin as an effective protector against doxorubicin-induced cardiotoxicity. Am J Physiol Circ Physiol 2002; 283: 254-263.

33. Öz E, Erbaş D, Sürücü HS, Düzgün E. Prevention of doxorubicininduced cardiotoxicity by melatonin. 2006; 282: 31-37.

34. Othman AI, El-Missiry MA, Amer MA, Arafa M. Melatonin controls oxidative stress and modulates iron, ferritin, and transferrin levels in adriamycin treated rats. Life Sci 2008; 83: 563-568.

35. Alam MF, Khan G, Safhi MM, et al. Thymoquinone ameliorates doxorubicin-induced cardiotoxicity in swiss albino mice by modulating oxidative damage and cellular inflammation. Cardiol Res Pract 2018; 1-6.
36. Xiao J, Ke Z-P, Shi Y, Zeng Q, Cao Z. The cardioprotective effect of thymoquinone on ischemia-reperfusion injury in isolated rat heart via regulation of apoptosis and autophagy. J Cell Biochem 2018; 119: 7212-7218.

37. Mauriz JL, Collado PS, Veneroso C, Reiter RJ, Gonzalez-Gallego J. A review of the molecular aspects of melatonin's anti-inflammatory actions: Recent insights and new perspectives. Journal of Pineal Research 2013; 54: 1-14.

38. Ojha S, Azimullah S, Mohanraj R, et al. Thymoquinone protects against myocardial ischemic injury by mitigating oxidative stress and inflammation. Evidence-Based Complementary and Alternative Medicine $2015 ; 1-12$.

39. Noda Y, Mori A, Liburdy R, Packer L. Melatonin and its precursors scavenge nitric oxide. J Pineal Res 1999; 27: 159-163.

40. Sarvazyan NA, Askari A, Huang W-H. Effects of doxorubicin on cardiomyocytes with reduced level of superoxide dismutase. Life Sci 1995; 57 (10): 1003-1010.

41. Agarkov AA, Popova TN, Matasova LV. The effect of melatonin on the antioxidant status of rats with type II diabetes mellitus. Biomed Chem 2012; 6 (3): 231-236. 